\title{
Digital Media Technology Applied in Animation Teaching
}

\author{
Jicheng Cong ${ }^{1 *}$ and Buqu Zeng ${ }^{2}$ \\ Huanghuai University.Zhumadian,Henan.China.463000 \\ ${ }^{1}$ congjicheng@sohu.com
}

\begin{abstract}
In the teaching practice of recent years, we analyzed the current teaching mode of animation curriculum, according to the characteristics that the digital media technology is lack of clear professional knowledge in the system of animation, being lack of the professional direction of setting the curriculum, as well as the feature of setting the curriculum like assorted cold dishes, it predicted the specialized talented person's demand, putting forward the target and basic ideas of the reform of teaching the animation curriculum.
\end{abstract}

Keywords: Digital media technology; animation curriculum; Teaching mode

\section{Introduction}

Digital media is a new industry that makes use of modern computer processing technology, storage technology and digital information technology, based on the traditional media. It mainly includes the digital animation, network games, digital video and so on. The software technology and computer hardware expert group of National 863 Program gives a new definition on "digital media", by writing 2005 White Paper on Technology Development of Chinese Digital Media: digital media is works with digital content, with the modern network as the main carrier of communication, through the perfect service system, distributing to the terminal and the whole process of having consumption with users. Therefore, the major of digital media technology took the technical courses as the skeleton is the inherent requirement. The technology courses of American digital media technology major mainly included the following categories (American CIP-2000): computer software technology, Webpage, digital/multimedia and information resource designing technology, publishing technology, pre-publishing/desktop publishing and digital image designing technology, animation, interactive technology, video and special effects technology, data modeling / database and warehouse management technology, etc., The technology courses of that the major of digital media technology had in our country accounted for more than $80 \%$ of the total courses (including cross animation courses), which basically realized the structuring system of the courses that the technology courses as the main course.But most technical courses are blind in selecting the courses, which are lack of the internal logic and can not become core skills to support the professional direction of the major. The setting of technology courses is shown as Figure 1.

Digital media major can be said to be a new special major that can keep pace with times, in order to enable students to better adapt to the demands of market, we are doing research and practice on animation education of the digital media technology major. This paper proposed the existing problems in the mode of animation education, discussing the teaching reform project of the digital media animation major.

${ }^{*}$ Corresponding Author 


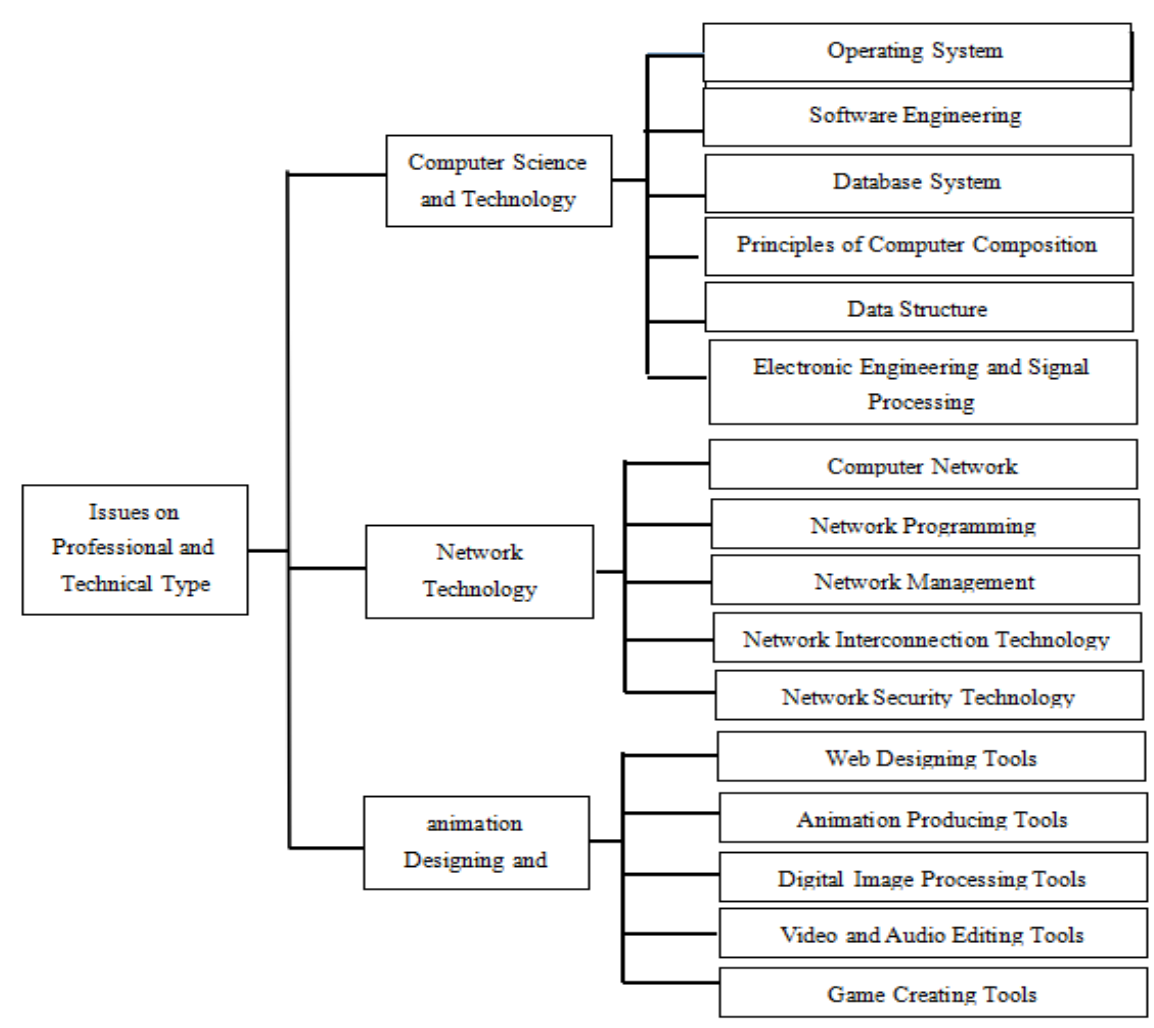

Figure 1. Courses of Technologies

\section{The Application of Digital Media Technology in Animation Teaching}

During the process of setting the professional courses, we fully considered the target of cultivating professional talents as well as the demand of the oriented industry of this major, firstly, we clear the professional orientation of the main major, based on the professional direction of the main major, we took the major of "typesetting system" and "multimedia design technology" as the two auxiliary direction, in order to facilitate the employment of graduates who can have wider range of adaptability and flexibility for jobs. During the process of designing the curriculum, combining the technology, animation and humanities education organically through to the professional teaching and practical process, which can make the students have skills and techniques with good comprehensive accomplishment for occupations. The course structure of this major took the ability of the digital media industry as the main line, the curriculum is covered with the animationistic quality, the basic theory of occupation, the technical ability of occupation, the development of occupational quality and humanistic and scientific quality, etc.,, Cultural qualities, humanistic and scientific quality put focus on developing students' humanities accomplishment and animationistic accomplishment, while the basic theory of occupation and the development of occupational quality is mainly to set up necessary professional basic courses in the curriculum and improve professional animation literacy, while the occupational ability put focus on the development and improvement of the students' occupational technical ability.

The main principles that are embodied in the professional teaching: the combination of skill training and animation performance; the combination of the traditional inheritance and innovation, the combination of training and teaching practice, the combination of the theory of technology with the theory of animation, the combination of classroom teaching with the practice of animation. It puts emphasis on the cultivation of comprehensive application of animation and skills, as well as the comprehensive ability and creative ability, so as to improve students' animation quality. 


\section{The Support and Promotion of Computer Network Technology for Animation Learning}

In recent ten years, with the rapid development of information technology, especially network technology as well as the popularization of computer equipment, computer technology has been widely used in education and teaching activities, such as computer assisted teaching, multimedia teaching, network teaching and other new teaching models. Because of the use of these modern teaching methods, during the teaching process, it can provide a large amount of information through the network, so as to achieve two-way communication and timely feedback, which also needs students to learn in more independent and initiative way. At the same time, more and more attention has been paid to the cultivation of students' independent learning ability all over the world, which also can be regarded as an effective means to cultivate students' creative ability. animation learning has become an important topic in the international education research, therefore, it is urgent to link network technology and animation learning effectively.

Network technology has brought an unprecedented meaningful support for the animation learning. This kind of support can not only lie in learners who can freely deal with learning time, choose learning space flexibly, choose an effective collaborative approach, independently access to learning resources in the external form. What's more, the most important thing is that this kind of support can promote learners to complete information expression independently, construct knowledge structure and show the characterization of different forms.

\section{Strategies for New Teaching Model of animation Learning for College English based on Network Platform}

Animation learning for college English based on network platform can play an important role in teaching and learning college English. The animation learning for college English based on network platform can be helpful to establish the students as the learning subject, who can engage themselves in the independent creative learning with the help of accessing to Internet. Under the computer network teaching environment, the larger the amount of language is inputted, the more interest can be aroused by learners, plus the interesting learning contents and images, which can be visual, audible, it can improve the learning interest of learners, all of the above can become the effective learning motivation factors.

Making full use of online resources and technical means can create language learning environment, which also can make the image of learning English more vivid. This kind of environment can encourage students be exposed to the language and social environment as much as possible, through the audible sound, the visible image, as well as the multimedia, network and virtual technology simulation, it can create language environment with sound and images, so as to realize a kind of virtual world. In this way, it can make the boring language learning and language usage cross over the distance of time and space, creating one vivid, interesting and authentic English language environment for students, which can help students understand the language and imitate the language.

The model of computer assisted teaching does not demand a unified learning progress, or the same learning content, without the same teaching requirements and fixed teaching time. All of this can make learners choose their own specific needs to make learning plan and set learning goals as well as learning methods according to their needs, interests, learning habits and so on. In this way, it can develop the learner's subject consciousness, emphasize self development as well, which is in line with the cultivation of animation learning, so as to enhance and improve learning motivation. 


\section{The Overall Design of Network Animation Learning Platform}

\subsection{The Overall Framework of Network Animation Learning Platform}

Animation learning under the network environment, the main media of which can be achieved through network platform. The construction of network learning platform is an important part of animation learning. The design of platform depends largely on the structure of platform's system whether it is scientific and reasonable or not, because the system structure is often the basement for network education platform, which can play a decisive role in the scope of application, function and performance of the system. In this study, it mainly adopts ASP.NET technology to build up network learning platform based on Internet. At the same time, it adopts Web browser /Web server / B/S/S three layer architecture, the overall architecture of network animation learning platform can be shown in Figure 2.

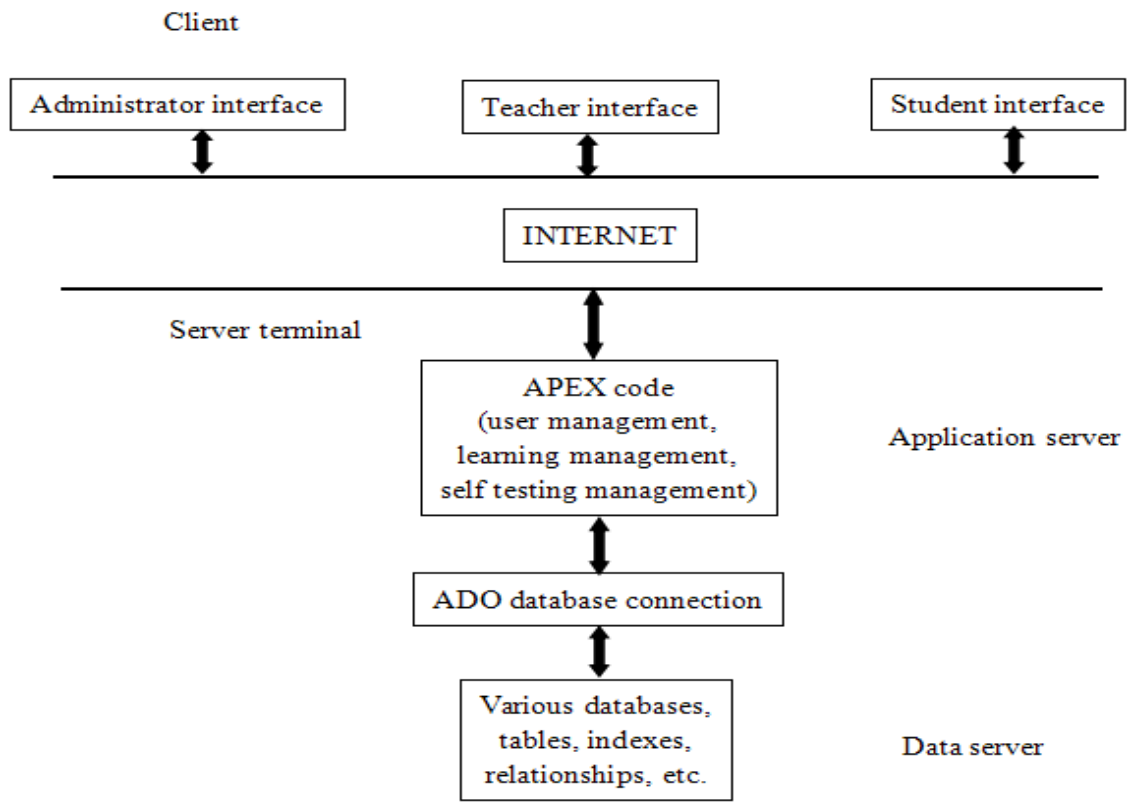

Figure 2. The Overall Structure of Network Learning Platform

\subsection{The Overall Function of Network Animation Learning Platform}

\subsubsection{Teacher Module}

This module can be divided into six sub modules, namely, public announcement management, curriculum management, homework management, student evaluation, online Question \& Answer, password modification. Announcement management module is mainly about the work that teachers issue and manage tasks related to teaching information. Curriculum management module is mainly on the management of animation learning materials, uploading the content of the independent learning to the system. Homework management module is mainly about the work on the release and maintenance of the information about homework, giving the evaluation on the students' homework, recording the students' performance. The students evaluation module is mainly about providing evaluation and recording the performance of students based on the students' animation learning, the implementation of the animation learning plan. The function of test management module can be shown in Figure 3. While Online Question \& Answer module is mainly an exchanging area that students can exchange ideas online, answering 
the questions that are proposed by the students.

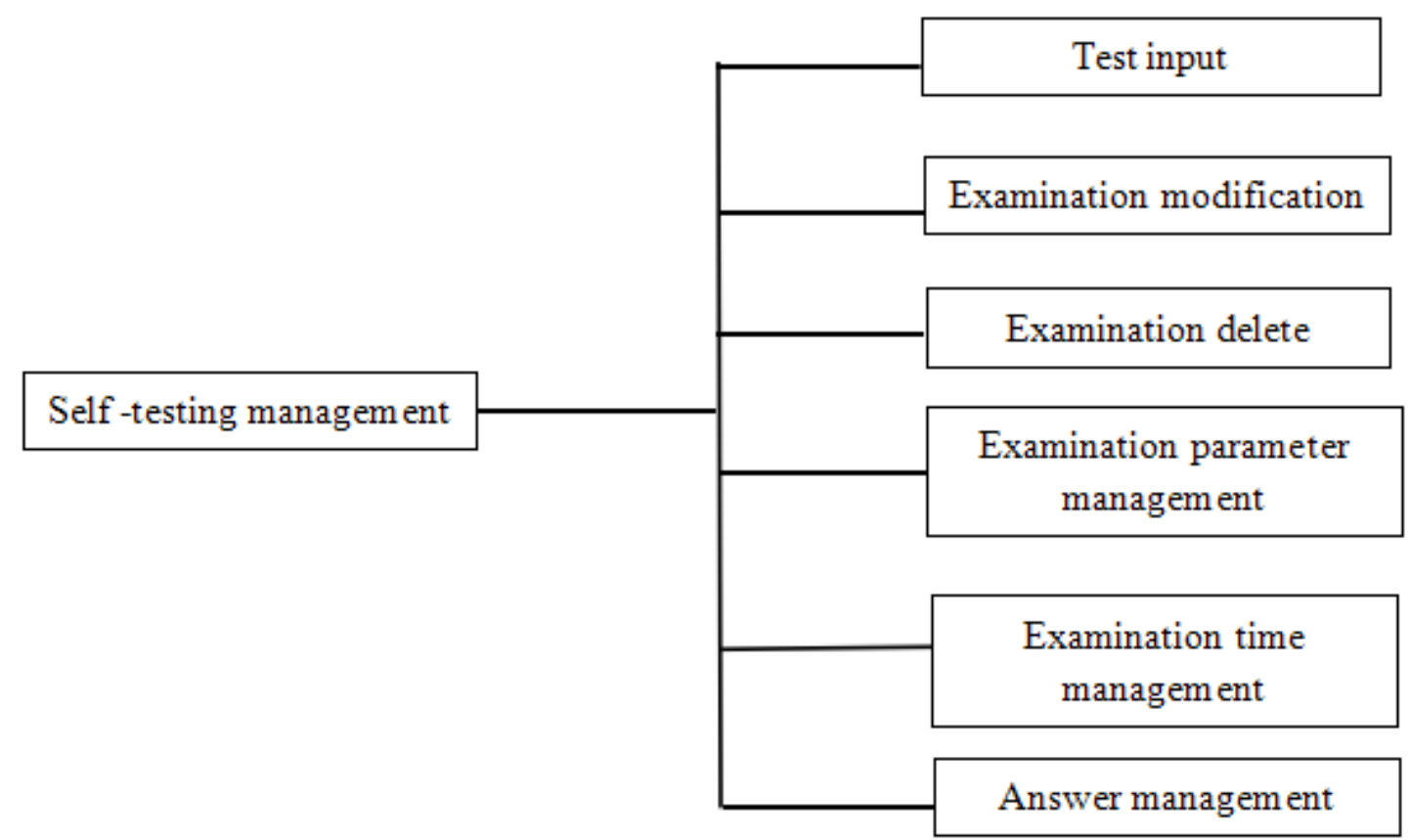

Figure 3. Self-Testing Management Module

\subsubsection{Computer Skills Training Combined with animation Performance}

The related digital media skills are the premise of the animationistic expression, without good and skillful computer skills, they may not have the exquisite animation performance. Professional learning model ability and animationistic accomplishment will not play its function. Such as the students majored in multimedia web site designing did not learn webpage designing software, thus, multimedia technology is difficult to express the designing concept, realizing the website's promotional function and service function. Meanwhile, only learning to use the related software without the animation creativity and performance, the designing website is lack of the feature of appreciation as well as the vitality. Skills take animation performance as the fundamental purpose, without the animationistic performance, the skills will lose its significance. In the past traditional teaching, it put emphasis on skills, looked down upon animation. In the curriculum of animation teaching, we adhere to the principle of the skills training and animationistic requirements at the same time, which can make students master the skills, at the same time, the ability of having animationistic experience, comprehension and expression ability can be improved significantly. The combined talents of digital media technology need the combination of technology and animation as well as humanities. Therefore, as the talents of digital media technology, not only as the expertise technical talent, but as a high-quality compound talents with humanities and cultural taste. In addition to mastering the solid professional skills, we should also have rich cultural knowledge and animationistic accomplishment.

\subsubsection{The Combination of Traditional Inheritance with Innovation}

After a long-term animation development, it formed a complete theoretical system and style, in animation teaching, we always adhere to respecting and learning Chinese and foreign outstanding media works, students are required to understand various related works with a number of designing concepts and follow with the advanced technologies in the world, so as to grasp the technical and animationistic style. On this basis, making 
great efforts to carry out the curriculum reform, putting the cultivation of students' creative designing capabilities in a prominent position, through creating the works, making comment on the works, showing the works, the creative ability of students can be improved. Creativity is the soul and core of all majors such as: digital media, animation designing, advertising and other professional courses. Because, in our designing curriculum system, there is a rare occurrence of special training course with animationistic quality and creativity. In the teaching practice of animation courses, it only focused on developing some professional training and skills that students should master, but it ignored the innovation ability. For example, in the graphic designing classes, during the process of teaching, teachers often teach PS technology to make software, so as to let students do in practice, and students should submit a picture works made by themselves at the end of the semester, but they rarely mentioned in the course about composition, color, and what kind of creative thought can meet the taste of modern generation. Teachers never blindly took foreign outstanding works to do case analysis during the teaching, or only learn little about the western culture, it will not occur that students do not know how exactly the creative ideas behind the works happened.

\subsubsection{The Combination of Method Training and Teaching Practice}

Digital media technology is a major with strong application. Experimental training courses and the construction of practical system is very important, trying to cultivate talents that the society needed should be based on practice, taking practice as the fundament. In cultivating the digital media technology talents, the mode of practice teaching generally has three kinds, one is the experimental course, another is through the centralized practice, the last is through the enterprise training.

We focus on the combination of classroom teaching and concrete practice, during the process of the teaching, it can make the students learn to master the method effectively, truly put knowledge into use, so as to adapt themselves to the future work, who can become useful talents and be welcomed by the industry and enterprises. Such as, when we open some main subjects, we can let the students fully appreciate their important roles of the courses in the subsequent courses and industry. On one hand, the curriculum should be closely combined with teaching contents, inviting the teachers with rich experience in the industry who had high academic attainments and practical experience have open lectures or teaching, which can make students learn professional knowledge vividly and intuitively, so as to stimulate the students interest in learning; on the other hand, the students can choose a topic to complete the designing works of the project, which can make students understand the methods and process of digital works in the course of studying stage and initially be engaged in the development and design of the project under the teacher's guide, laying better foundation for entering the industry for the creation of digital media.

Through the research, among the animation depanimationment that set up the professional digital media technology major, $90 \%$ of them set up two or more elective directions for the major, which can allow the students in grade three or four to choose their own choice of different professional direction according to the basis and characteristics. It is shown as Figure. 4, in the graph, the horizontal axis is the developing direction, the longitudinal axis is the number of the colleges in this direction, the most professional direction of each school set up is the game design and development, animation, film and television program production, digital media software development, etc., However, after the analysis, it also found out a number of problems, one of them is the direction of the professional digital media technology and digital media animations professional direction is the same, which can not reflect the characteristics of digital media technology major; secondly, setting the professional direction of the curriculum is a little more random, for example, the professional direction of animation production major that is set up by some universities just randomly selected three to four courses of the animation major of Communication University of China. 


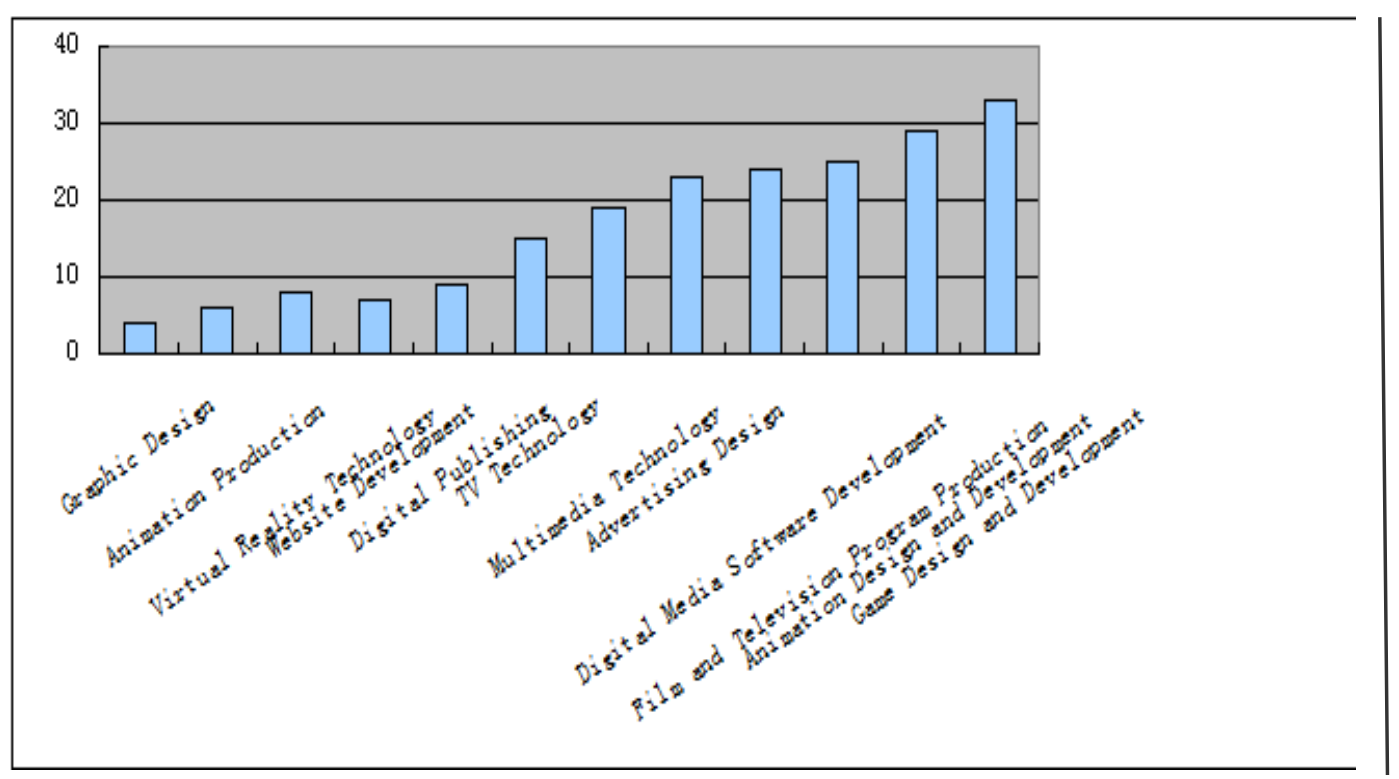

Figure 4. Different Professional Direction

Setting the professional direction of the major is the basis of the digital media technology major, generally, setting the professional direction should consider the following factors:

(1) Social needs, social needs can decide the employment of students, which can determine the survival and the development of the major;

(2) The actual situation of the school, taking the advantages of the school's resources, fostering the strengths and avoiding the weaknesses;

(3) Considering the actual condition of the students, such as the digital media technology of the second class colleges should highlight the application, namely " use information technology effectively, rather than develop information technology";

(4) Optimizing the design of the curriculum system, which should emphasize the internal relations between the courses,so as to avoid the overlapped contents and repeated contents.

\section{Conclusion}

The professionals that major in digital media technology animation should adhere to "application is the root ", we think we should do the following several aspects: one aspect is to construct the animation professional curriculum system to fit the training of the applied talents. Try to change the the high proportion of the basic theory of class teaching, as well as the condition of the shortage of students' practical ability. Another aspect is to change the traditional teaching mode and teaching methods. The traditional mode of teaching ,is teachers give speech, students listen, which can not play the role of the subjective initiative of students, the characteristics of digital media technology major decided to strengthen practical teaching, with the cultivation mode of joining the college and enterprise together, at the same time, strengthen the new curriculum under the concept of activity courses. The third aspect is to change the traditional way of evaluation. We must introduce work evaluation, project evaluation, evaluation on creative report into the evaluation system. 
International Journal of $u-$ and $\mathrm{e}-$ Service, Science and Technology

Vol.9, No. 9 (2016)

\section{References}

[1] J. Li, "Thinking of digital media professional education", Journal of science and technology, vol. 29, no. $02,(\mathbf{2 0 0 8})$.

[2] W. Zikai, "Design the teaching and the cultivation of creative ability", Journal of publishing and printing, vol. 2, (2008), pp. 59-60.

[3] L. Shi, "principle and the basis of curriculum theory, curriculum problems", Beijing: education science press, (2001).

[4] M. Huang, "New media and western digital animation theory", Tianjin: Tianjin people's publishing house, (2009).

[5] Y. Youquan, "animation transformation under the digital media", Beijing: China social sciences press, (2011).

[6] P. D. Maclntyre, "Toward a psychological model of strategy use”, Foreign Language Annals., vol. 27, (1994), pp. 185-195.

\section{Authors}

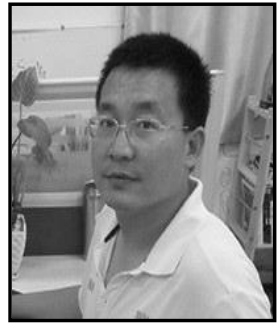

Jicheng Cong, assisted professor, Research direction: Computer analysis. Data mining

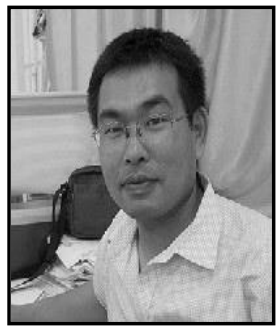

Buyu Zeng, professor, Research direction: Computer analysis. Data mining 